\title{
A view of Jamaica's murder victims, perpetrators \& the Impact of the 2010 Incursion
}

\author{
Fred Spiring \\ Bureau of Women's Affairs, Office of the Prime Minister, Kingston, Jamaica
}

Email address:

fspiring@mymts.net

\section{To cite this article:}

Fred Spiring. A View of Jamaica's Murder Victims, Perpetrators \& the Impact of the 2010 Incursion. Humanities and Social Sciences. Vol. 1, No. 3, 2013, pp. 92-100. doi: 10.11648/j.hss.20130103.13

\begin{abstract}
In this manuscript we investigate homicides in Jamaica for the period 2007-2012. Several views of the available data are presented in an attempt to highlight statistically significant changes in murder rates as well as to indicate areas where there has been virtually no change in frequencies or patterns. As we begin to better understand the dynamics behind the victims and perpetrators of murder through statistical analyses, those initiatives that target crime and homicide reduction should become more efficient and effective. Some commentary is included in order to provide background and support for the statistical tools used.
\end{abstract}

Keywords: Homicide Rates, Perpetrator, Victim, Tivoli Gardens

\section{Introduction}

The United Nations Office on Drugs and Crime (UNODC) homicide report [1] lists Jamaica among the top five of the 207 reporting countries in terms of murder rate per 100,000 inhabitants. The report indicated that in 2009 Jamaica's murder rate was 61.6 per 100,000. Similarly, in 2009, Vision 2030 Jamaica [2] addressed the high murder rates indicating that 'While Jamaica's total crime rate declined over the last ten years, violent crimes have been increasing at a disconcerting rate. The murder rate, in particular, has almost doubled in every decade since Independence'. To add context to these comments, the Vision 2030 Jamaica document was published in 2009 and was based on data up to and including 2008; while Jamaica gained independence in 1962. In this manuscript we investigate the homicide rates in Jamaica for the period 2007-2011 from a statistical perspective. All murder frequencies are as reported by the Jamaica Constabulary Force (JCF) with all analyses made in an attempt to better understand homicide in Jamaica.

A systematic examination of the victims of murder, the perpetrators of murder, regional aspects of Jamaica that have higher than expected murder rates and the impact of a policing action are undertaken. All analyses are based on data provided by the JCF and presented from a variety of perspectives in an attempt to better understand the incidents of murder in Jamaica. As we begin to better understand the dynamics behind the victims and perpetrators of murder through statistical analyses, the programs that target crime and homicide reduction should become more efficient and effective. The manuscript illustrates innovative techniques for looking at data over time, as well as illustrating some traditional techniques in assessing age and sex characteristics of both victims and perpetrators of murder in Jamaica. Finally we will look at the impact on homicide rates arising from 'The Incursion in Tivoli Gardens' and subsequent policing strategies. We welcome feedback on the analyses and the readers' inferences and/or conclusions drawn. The data has been included in order to encourage others to investigate and present additional views.

\section{The Data}

The JCF distributed data for 'Victims of Major Crimes for the Years 2007-2011' by age group and sex in June 2012 [3]. In the report, the JCF included six main categories of Major Crime including Murder, Shooting, Robbery, Break-in, Larceny and Rape. Each Major Crime was disaggregated by sex and age with the exception of rape, as rape as defined in Jamaica has female victims only. The age brackets were intervals of 5 years starting at age 0 and continuing to age 99 Table 1 contains the age disaggregated frequencies associated with the Major Crime of Murder over the period 2007-2011 for Female and Male victims. This data was augmented with information included in the 'Jamaica 
Constabulary Force Periodic Major Crime Statistics Review-January 1, 2012-March 31, 2012 and Comparison 2011, 2010 and 2009' [4]. The JCF (via JAMStats 2010) was the data source for perpetrators of murder [5] for the period 2008-2010. The Economic and Social Survey Jamaica (ESSJ) 2011 [6] was used as a source for demographic data.

All data provided by the JCF comes with the warning 'Figures included in this document are subjected to change due to discoveries from on-going investigations'. All data provided by the JCF has been assumed correct and has not been analyzed for accuracy. As well, there has been no assessment of unreported or under reported information. Population figures for 2011 are denoted by the ESSJ as provisional.

Table 2 summarizes the results from Table 1 using the ESSJ population figures to arrive at the Homicides per 100,000 inhabitants rate for Jamaica. These figures are similar but not identical to those reported by UNODC [1]. Since the homicide rate based on the JCF and ESSJ data is higher than that reported by the UNODC it is assumed that the discrepancies would not affect the UNODC rankings and the inferences drawn. The discrepancies appear to arise from the population counts used by UNODC in determining the Homicide rate for Jamaica. All calculations and summaries included in the manuscript are based on the JCF and ESSJ data.

Table 1. Murder Victim frequencies for the period 2007-11 by age and sex

\begin{tabular}{|c|c|c|c|c|c|c|c|c|c|c|}
\hline $\begin{array}{l}\text { Year } \\
\text { Sex }\end{array}$ & $\begin{array}{c}2011 \\
\text { M }\end{array}$ & $\begin{array}{c}2011 \\
\text { F }\end{array}$ & $\begin{array}{c}2010 \\
\text { M } \\
\end{array}$ & $\begin{array}{c}2010 \\
\text { F }\end{array}$ & $\begin{array}{r}2009 \\
\text { М }\end{array}$ & $\begin{array}{c}2009 \\
\text { F }\end{array}$ & $\begin{array}{c}2008 \\
\text { M } \\
\end{array}$ & $\begin{array}{c}2008 \\
\text { F }\end{array}$ & $\begin{array}{r}2007 \\
\text { M } \\
\end{array}$ & $\begin{array}{c}2007 \\
\text { F }\end{array}$ \\
\hline $0-4$ & 1 & 2 & 3 & 0 & 4 & 1 & 2 & 2 & 1 & 1 \\
\hline $5-9$ & 4 & 3 & 5 & 3 & 3 & 1 & 0 & 2 & 2 & 1 \\
\hline $10-14$ & 6 & 1 & 5 & 2 & 7 & 7 & 13 & 4 & 7 & 4 \\
\hline $15-19$ & 88 & 7 & 100 & 11 & 144 & 15 & 130 & 20 & 112 & 19 \\
\hline $20-24$ & 147 & 14 & 193 & 22 & 252 & 21 & 254 & 18 & 229 & 30 \\
\hline $25-29$ & 143 & 12 & 233 & 21 & 291 & 22 & 228 & 24 & 257 & 13 \\
\hline $30-34$ & 139 & 11 & 172 & 16 & 199 & 13 & 198 & 9 & 189 & 14 \\
\hline $35-39$ & 119 & 12 & 153 & 16 & 140 & 17 & 201 & 18 & 181 & 14 \\
\hline $40-44$ & 106 & 12 & 117 & 17 & 143 & 19 & 116 & 24 & 122 & 19 \\
\hline $45-49$ & 80 & 9 & 87 & 10 & 99 & 11 & 90 & 15 & 107 & 11 \\
\hline $50-54$ & 54 & 9 & 69 & 11 & 57 & 6 & 44 & 3 & 48 & 3 \\
\hline $55-59$ & 24 & 7 & 36 & 6 & 50 & 6 & 34 & 4 & 40 & 4 \\
\hline $60-64$ & 15 & 5 & 26 & 0 & 25 & 4 & 16 & 8 & 20 & 2 \\
\hline $65-69$ & 16 & 4 & 12 & 1 & 17 & 4 & 16 & 4 & 18 & 1 \\
\hline $70-74$ & 7 & 6 & 6 & 1 & 8 & 0 & 12 & 2 & 12 & 2 \\
\hline $75-79$ & 3 & 1 & 13 & 1 & 10 & 0 & 10 & 1 & 6 & 0 \\
\hline $80-84$ & 4 & 0 & 2 & 3 & 2 & 1 & 1 & 1 & 4 & 1 \\
\hline $85-89$ & 0 & 0 & 1 & 1 & 4 & 2 & 1 & 0 & 1 & 1 \\
\hline $90-94$ & 0 & 0 & 0 & 0 & 1 & 3 & 0 & 0 & 0 & 1 \\
\hline $95-99$ & 0 & 0 & 0 & 1 & 0 & 0 & 0 & 0 & 0 & 0 \\
\hline Unknown & 58 & 4 & 65 & 2 & 71 & 3 & 88 & 6 & 76 & 10 \\
\hline Total & 1014 & 119 & 1298 & 145 & 1527 & 156 & 1454 & 165 & 1432 & 151 \\
\hline
\end{tabular}

Table 2. Homicide Rates per 100,000 for the period 2007-2011

\begin{tabular}{lllll}
\hline Year & 2011 & 2010 & 2009 & 2008 \\
\hline Homicides & 1133 & 1443 & 1683 & 1619 \\
Population & 2709300 & 2703600 & 2698800 & 2692400 \\
$\begin{array}{l}\text { JCF \& ESSJ } \\
\text { Homicides Per 100,000 }\end{array}$ & 41.8 & 53.4 & 62.4 & 60.1 \\
$\begin{array}{l}\text { UNODC } \\
\text { Homicides Per 100,000 }\end{array}$ & 40.9 & 52.2 & 61.6 & 59.0 \\
\hline
\end{tabular}




\section{Victims' Analyses}

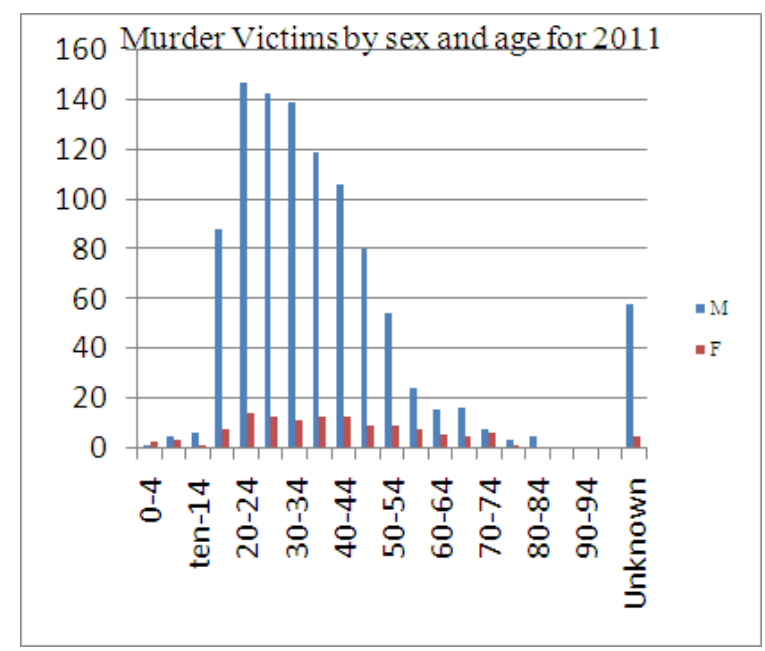

Figure 1. Murder Victim Frequencies by sex and age for 2011.

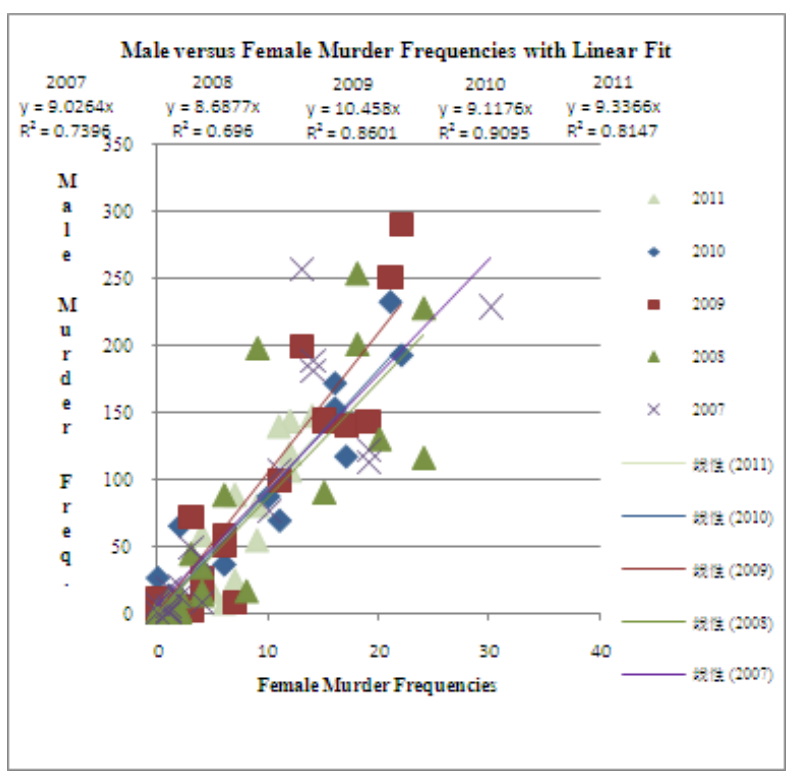

Figure 2. Male versus Female Murder freq. by age group for 2007-11.

Examining the data for the year 2011 in both table form (Table 1) and graphical form (Figure 1) immediately suggests that murder rates for Male victims are significantly higher than equivalent rates for Females. Over the critical age brackets of 15 through 64 the Male murder frequencies are 6 to 12 times larger than the Female frequencies in 2011. This pattern of Male Murders, being an order of magnitude larger than Females, is consistent for each year 2007 through 2011 (see Figure 2). Using ordinary least squares (OLS) linear fits for Male murder frequencies versus Female murder frequencies and examining the slopes of the fitted lines (i.e., 8.7 to 10.5 , see Figure 2) reinforces that the Male frequencies tend to be an order of magnitude larger than the Female frequencies. For each year over the 2007-2011 period, males represent $90 \%$ of the murder victims in Jamaica.
Figure 3 illustrates the repeated yearly pattern (2007-2011) for both Female and Male victims that sees murder frequencies peek in the $20-24$ or $25-29$ age brackets and decline steadily through to the 60-64 age bracket. In 2011 the average age of Male victims is 33 (38 for Females) with just over $28 \%$ of the Male victims in their twenties (20-29) while the 30-39 year old group represents just over $25 \%$ of Male victims. These combined age brackets (i.e., 20-39) represent 54\% of the Male victims in 2011. Approximately $90 \%$ of all victims fall in the age group 15-64, a group that in 2011 represented $64 \%$ of the Jamaican population. Although not identical, the frequency profiles for both Females and Males over the age groups are remarkably similar for each year analyzed. Males between the ages of 20 and 39 consistently represent $50 \%$ of all murder victims in Jamaica.

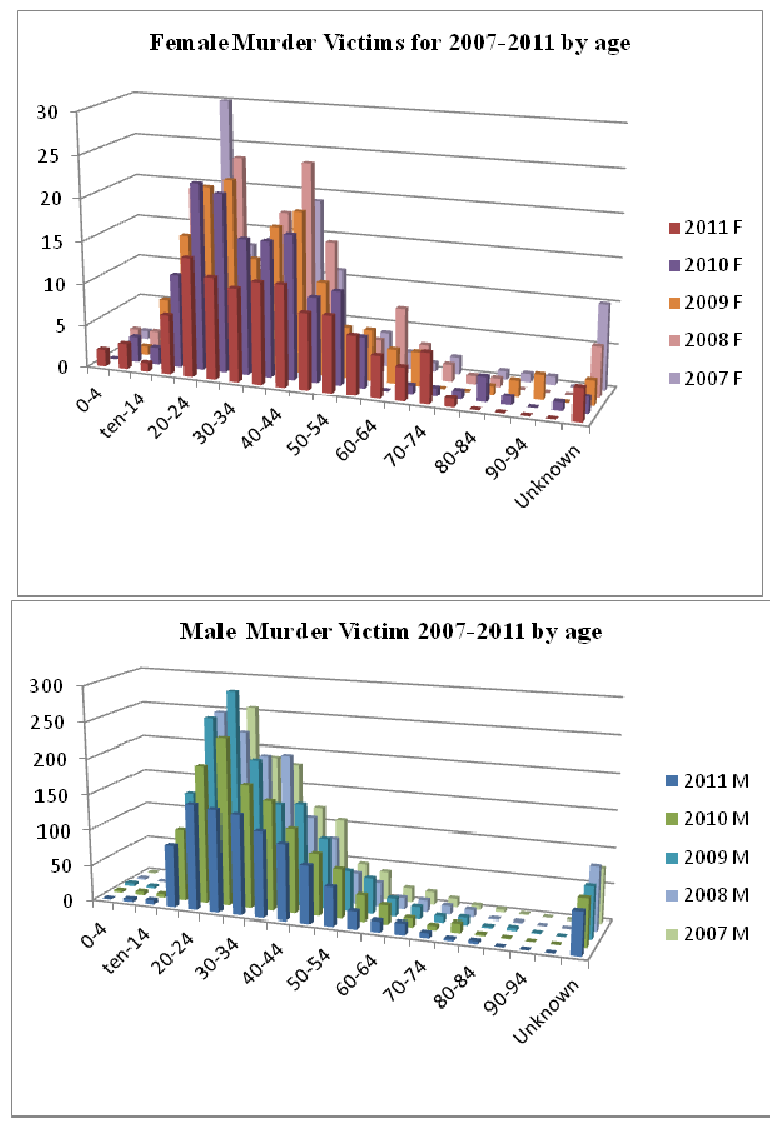

Figure 3. Female \& Male Murder Victim Freq. for 2007-11 by age

Figures 4 and 5 illustrate the annual murder frequencies for Females and Males over the period 2007-2011 and include linear and 2nd degree polynomial fits respectively. Both the linear and polynomial fits use OLS to determine model estimates. The OLS method chooses the best fit in the class (i.e., linear or polynomial of degree 2) by minimizing the overall squared distance of the observed points to the actual fit. The plots suggest that the annual number of murders appears to be in slight decline for both Males and Females. Neither the Male or Female linear trend, although negative, is statistically significant at the 
0.05 level (Figure 4), but both 2nd order polynomial fits are statistically significant (Figure 5). These plots suggest an overall decline in the murder frequencies for both Females and Males over the period 2007-2011. In particular, 2010 and 2011 represent declines in the homicide rates from the peak in 2009. Extrapolating the linear models for Males and Females out to 2012, sees a prediction of 1047 Male victims and 122 Female victims for an estimated total of 1169 homicides for 2012. The current homicide count for the period January 1, 2012 - November 30, 2012 is 1007, suggesting that the model prediction of 1169 homicides seems reasonable.

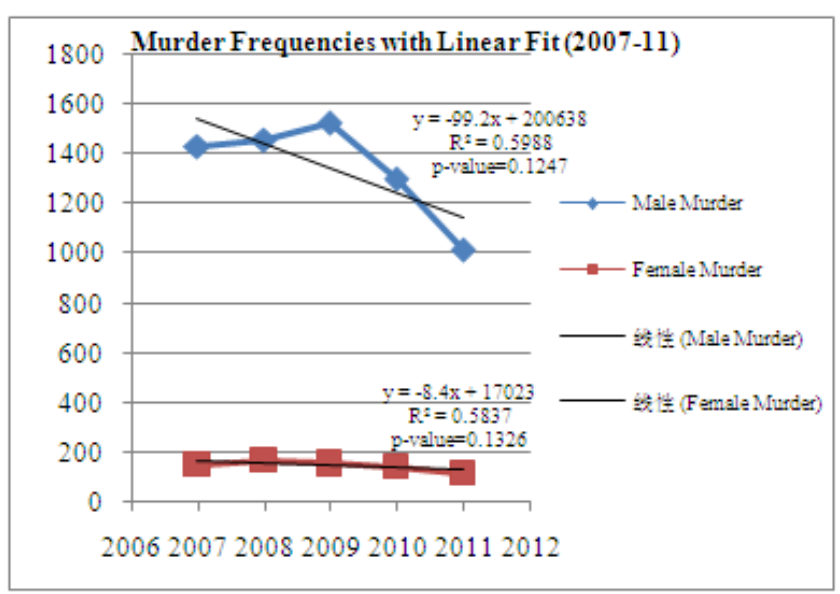

Figure 4. Linear Fits for Disaggregated Murder data by sex

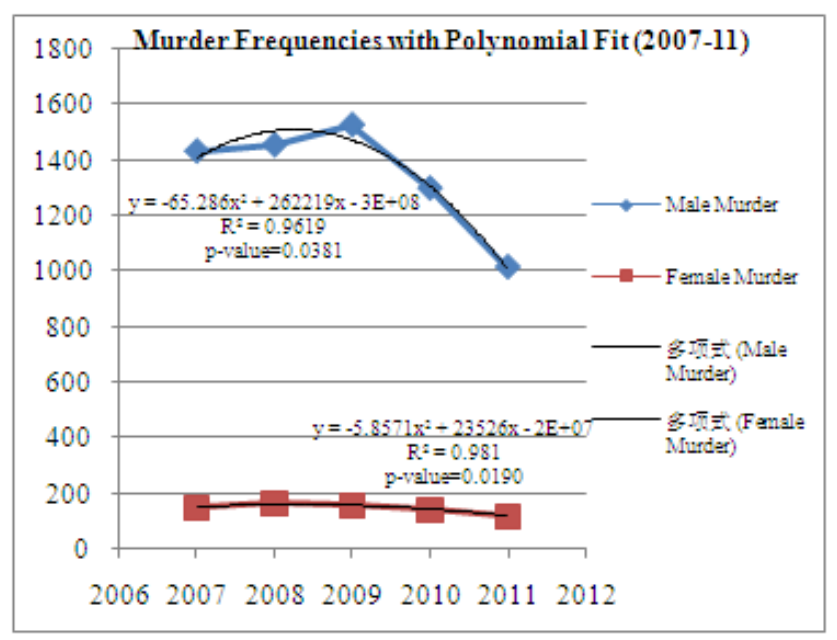

Figure 5. $2^{\text {nd }}$ Degree Poly. Fits for Disaggregated Murder data by sex

Although the $2^{\text {nd }}$ degree polynomial fits are statistically significant for both Females and Males, extrapolating beyond the range of data (e.g., predicting the number of murders for 2012) is not recommended. Note that these trend analyses are based on five data points only; several additional data points (e.g., 2012, 2013, ...) are recommended in order to confirm the sustainability and significance of the trends.

As noted earlier, Vision 2030 Jamaica [page 108, 2] discusses the high murder rates in Jamaica and indicates that 'While Jamaica's total crime rate declined over the last ten years, violent crimes have been increasing at a disconcerting rate. The murder rate, in particular, has almost doubled in every decade since Independence.' The publication date for Vision 2030 Jamaica was 2009 and included data up to and including 2008. Since its publication the Murder rate for both Males and Females has been dropping as detailed in Figures 4 \& 5. Jamaica's declining homicide rate is encouraging. Preliminary results for 2012 appear to follow this trend with the JCF reporting 1007 homicides through November 30, 2012. These declines do not appear large enough to take Jamaica out of UNODC's top 10 list of homicide rates.

Augmenting the JCF Crime Statistics with parish population figures for 2011 [6], allows us to examine the frequencies of murder by geographic districts in Jamaica. Jamaica consists of 14 contiguous parishes with the parishes of Kingston and St. Andrews often being combined resulting in 13 distinct regions (see Figure 6).

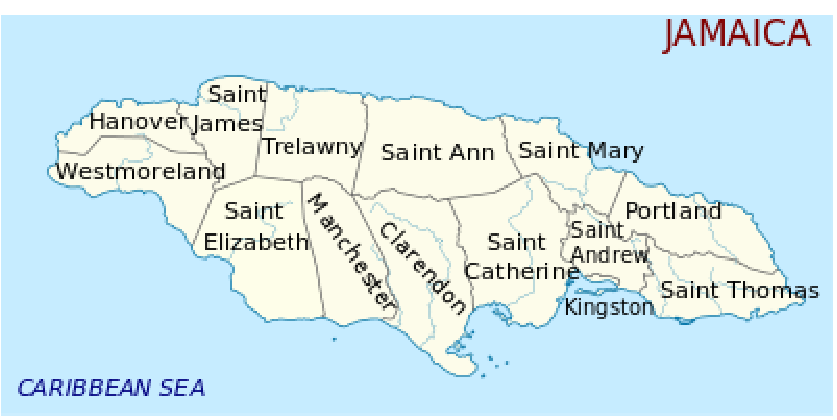

Figure 6. Parishes of Jamaica

Table 3. Actual freq., Expected freq. and population by Parish

\begin{tabular}{|c|c|c|c|}
\hline Parish & Murder & E(Murder) & population \\
\hline Kingston \& St. Andrew & 328 & 280.1867641 & 670000 \\
\hline St. Catherine & 300 & 209.8055217 & 501700 \\
\hline St. James & 158 & 77.61591555 & 185600 \\
\hline Trelawny & 19 & 31.82419813 & 76100 \\
\hline Westmoreland & 62 & 61.0138043 & 145900 \\
\hline Hanover & 15 & 29.44051969 & 70400 \\
\hline St. Mary & 23 & 48.13357694 & 115100 \\
\hline St. Ann & 41 & 72.97401543 & 174500 \\
\hline Portland & 10 & 34.62606577 & 82800 \\
\hline Manchester & 32 & 80.37596427 & 192200 \\
\hline Clarendon & 77 & 103.7527406 & 248100 \\
\hline St. Elizabeth & 31 & 63.60657734 & 152100 \\
\hline St. Thomas & 37 & 39.64433618 & 94800 \\
\hline Totals & 1133 & & 2709300 \\
\hline
\end{tabular}




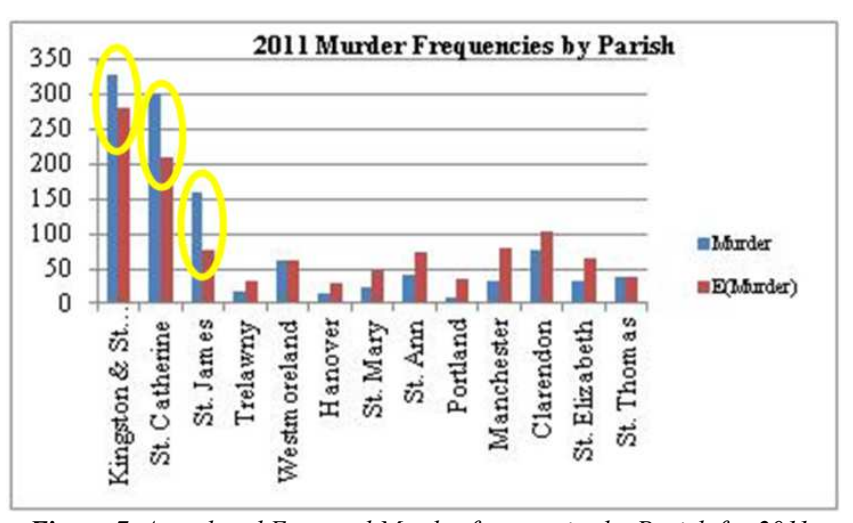

Figure 7. Actual and Expected Murder frequencies by Parish for 2011

The geographical size and population of the parishes vary substantially. The least populated parish (Hanover) reported 70,400 inhabitants in 2011 while the most populace parish (Kingston \& St. Andrew) reported 670,000 inhabitants. Based on the number of murders Jamaica wide in 2011, and the parish population figures for 2011, the expected number of murders for each parish was calculated. Table 3 includes the actual number and expected number of murder victims based on Parish population size. A Goodness-of-Fit test reveals that the actual frequencies vary significantly from the expected frequencies ( $p$-value $<0.0001$ ), suggesting that there are parishes exhibiting murder frequencies different than expected based on actual population counts. Further investigation suggests that the parishes of Kingston \& St. Andrew, St. Catherine and St. James have higher murder frequencies than would be expected based on population, while the remaining parishes have either as expected or smaller murder frequencies. The actual and expected frequencies by parish appear in Figure 7. Those parishes with significantly higher actual frequencies are highlighted.

Table 4. Perpetrator frequencies by age and sex for 2008-2010

\begin{tabular}{ccccccccccccc}
\hline & Female & Male & & & Female & Male & & & Female & Male \\
\hline 2008 & $12-14 \mathrm{yr}$ & 0 & 2 & 2009 & $12-14 \mathrm{yr}$ & 0 & 1 & 2010 & $12-14 \mathrm{yr}$ & 0 & 3 \\
2008 & $15-19 \mathrm{yr}$ & 4 & 65 & 2009 & $15-19 \mathrm{yr}$ & 4 & 70 & 2010 & $15-19 \mathrm{yr}$ & 0 & 86 \\
2008 & $20-24 \mathrm{yr}$ & 2 & 132 & 2009 & $20-24 \mathrm{yr}$ & 4 & 131 & 2010 & $20-24 \mathrm{yr}$ & 4 & 169 \\
2008 & $25-29 \mathrm{yr}$ & 5 & 99 & 2009 & $25-29 \mathrm{yr}$ & 1 & 128 & 2010 & $25-29 \mathrm{yr}$ & 3 & 125 \\
2008 & $30-34 \mathrm{yr}$ & 0 & 63 & 2009 & $30-34 \mathrm{yr}$ & 7 & 75 & 2010 & $30-34 \mathrm{yr}$ & 0 & 64 \\
2008 & $35-39 \mathrm{yr}$ & 2 & 26 & 2009 & $35-39 \mathrm{yr}$ & 3 & 43 & 2010 & $35-39 \mathrm{yr}$ & 1 & 33 \\
2008 & $40-44 \mathrm{yr}$ & 1 & 14 & 2009 & $40-44 \mathrm{yr}$ & 0 & 17 & 2010 & $40-44 \mathrm{yr}$ & 2 & 25 \\
2008 & $45-49 \mathrm{yr}$ & 0 & 14 & 2009 & $45-49 \mathrm{yr}$ & 1 & 6 & 2010 & $45-49 \mathrm{yr}$ & 1 & 22 \\
2008 & $50-54 \mathrm{yr}$ & 0 & 2 & 2009 & $50-54 \mathrm{yr}$ & 0 & 5 & 2010 & $50-54 \mathrm{yr}$ & 0 & 7 \\
2008 & $55-59 \mathrm{yr}$ & 0 & 1 & 2009 & $55-59 \mathrm{yr}$ & 0 & 3 & 2010 & $55-59 \mathrm{yr}$ & 0 & 1 \\
2008 & $60-64 \mathrm{yr}$ & 0 & 1 & 2009 & $60-64 \mathrm{yr}$ & 0 & 4 & 2010 & $60-64 \mathrm{yr}$ & 0 & 1 \\
2008 & $65-69 \mathrm{yr}$ & 0 & 0 & 2009 & $65-69 \mathrm{yr}$ & 0 & 0 & 2010 & $65-69 \mathrm{yr}$ & 0 & 1 \\
2008 & $70-74 \mathrm{yr}$ & 0 & 0 & 2009 & $70-74 \mathrm{yr}$ & 0 & 0 & 2010 & $70-74 \mathrm{yr}$ & 0 & 0 \\
2008 & $75-80 \mathrm{yr}$ & 0 & 1 & 2009 & $75-80 \mathrm{yr}$ & 0 & 1 & 2010 & $75-80 \mathrm{yr}$ & 0 & 0 \\
2008 & Unknown & 0 & 16 & 2009 & Unknown & 0 & 9 & 2010 & Unknown & 0 & 11 \\
2008 & Total & 14 & 436 & 2009 & Total & 20 & 493 & 2010 & Total & 11 & 548 \\
\hline
\end{tabular}

\section{Perpetrators' Analyses}

Having looked at murder victims from an age and sex perspective, it is also possible to examine similar profiles associated with the perpetrators of murder in Jamaica. Figure 8 provides frequencies by age bracket for a) murders committed by Male perpetrators and b) murders committed by Female perpetrators for the period 2008-2010. Meanwhile Figure 9 provides frequencies by age bracket for a) murders committed by Male perpetrators and b) murders committed by Female perpetrators in 2010. The data appears in Table 4. Murder in Jamaica is overwhelmingly a Male dominated action as witnessed by the fact that only 14 of 450 , 20 of 517 and 11 of 559 perpetrators in 2008, 2009 and 2010 respectively were Female. Similar to the victims' profile where on a yearly basis $90 \%$ of the homicide victims are male, more than $95 \%$ of the perpetrators are male. Each year the frequencies peak in the 20-29 age groups and decline steadily through to the 45-49 age bracket reaching nominal values in the over 50 brackets. Note that the initial age bracket is $12-14$ years, not 10-14 years, reflecting the fact that youth under 12 cannot be charged with a crime.

The Female perpetrator and victim murder rates for 2010 
as depicted in Figure 10 have been included for completeness only. The Female perpetrator data is too sparse to be effectively disaggregated by age. The Male perpetrator and victim murder rates for 2010 (Figure 11) suggest that the age profile of the perpetrators is different from that of the victims. The average age of the Male perpetrators in 2010 was 27 years with over $53 \%$ of the perpetrators in their twenties (20-29) while the 30-39 year old group represented just over $17 \%$ of Male perpetrators. Overall Males in the age group 20 through 39 represent $70 \%$ of the perpetrators of homicide on a yearly basis, but only $50 \%$ of the victims. $98 \%$ of the perpetrators were less than 50 years old.

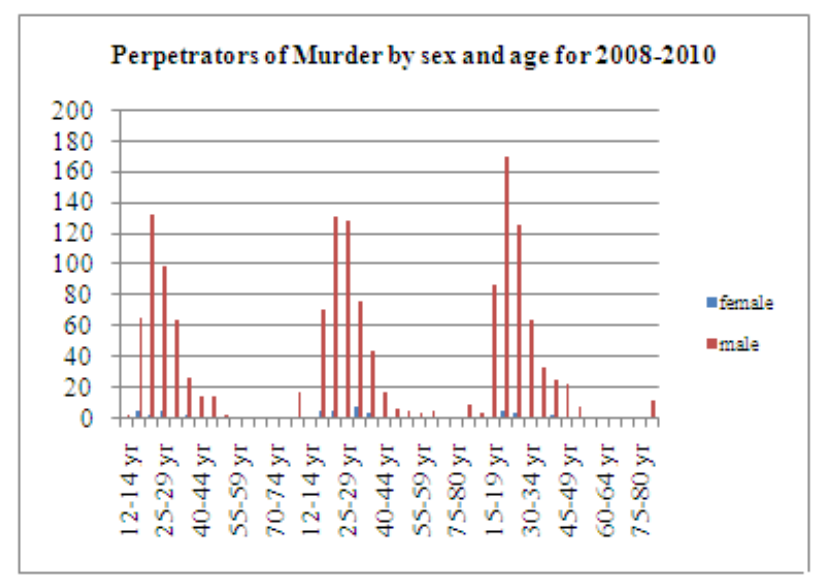

Figure 8. Perpetrators by sex and age for 2008-10

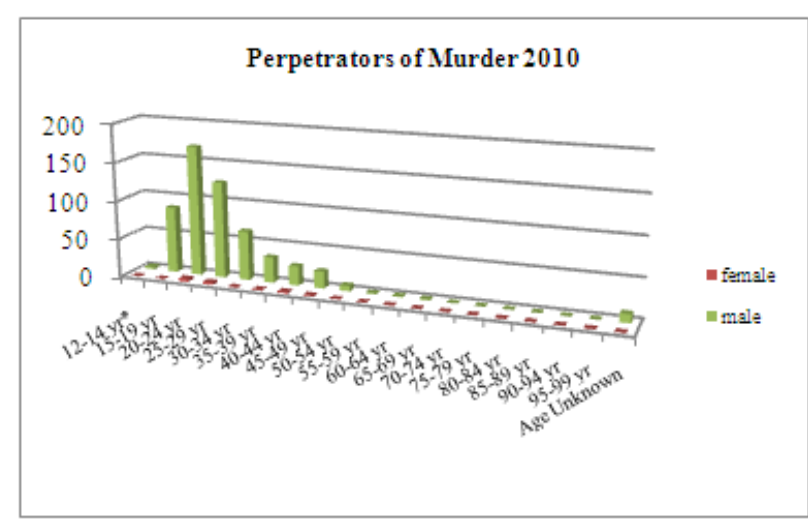

Figure 9. Perpetrators of Murder for 2010 by age and sex

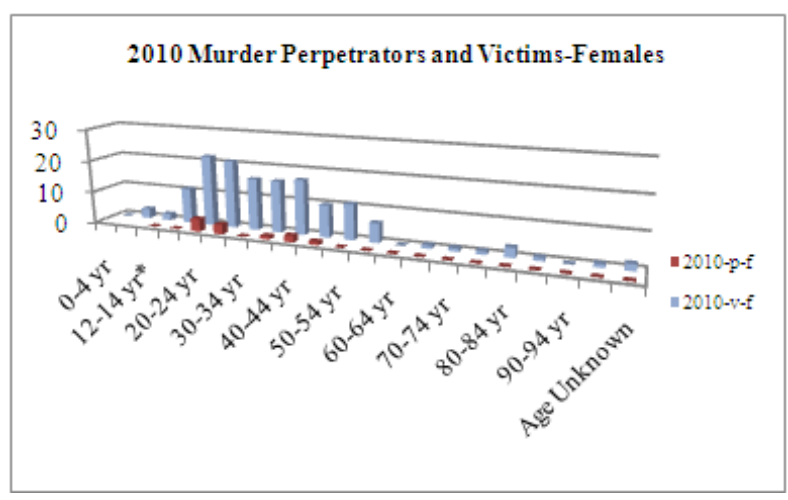

Figure 10. Female Victims \& Perpetrators by age for 2010

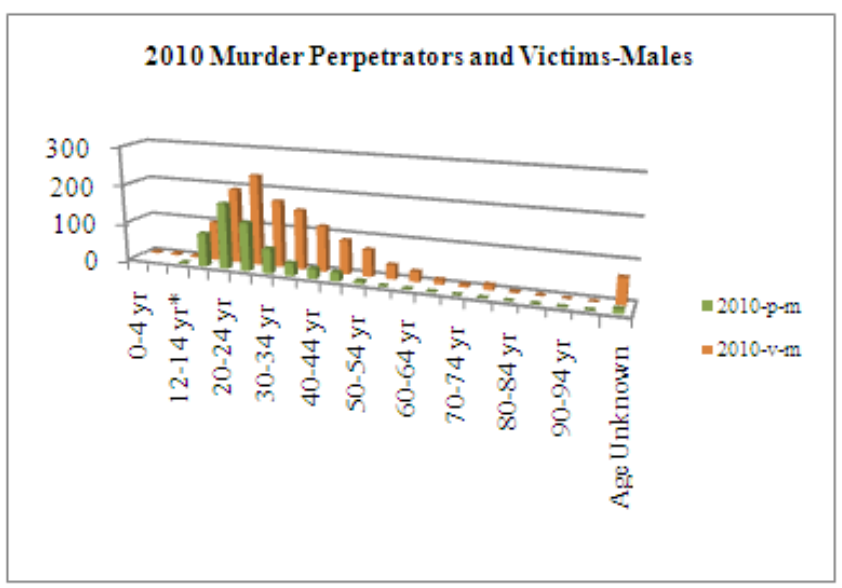

Figure 11. Male Victims \& Perpetrators by age for 2010

\section{The Impact of a Policing Action}

In May of 2010, a joint action on behalf of the Jamaica Defense Force (JDF) and the Jamaica Constabulary Force saw Tivoli Gardens and Denham Town, also known as West Kingston Jamaica, swept by the joint forces in search of its don Christopher 'Dudus' Coke [7]. Coke was wanted by the United States for drug smuggling and gun running. The event has become known as 'The Incursion' and resulted in 73 known deaths. Coke was later extradited to the US and has since been incarcerated. Subsequent to 'The Incursion' a police presence has been maintained in Tivoli Gardens. Much discussion surrounding the lead-up to and impact of 'The Incursion' [8] has taken place; we look at the periods before and after 'The Incursion' from a statistical perspective and attempt to quantify the impact.

The JCF published the Periodic Major Crime Statistics Review for January 1, 2012 through March 31, 2012 [4] that included monthly murder victim data for the period January 2009 to March 2012 (see Table 5). The frequencies included in the report were not disaggregated by sex and represent the total number of victims on a monthly basis.

Figure 12 is a time plot (January 1, 2009 through March 31,2012 ) of the monthly murder frequencies, that has been augmented with Individual and Moving Range ( $\mathrm{r}=3$ ) control chart limits. The control limits for both the Individuals chart (i.e., the monthly murder frequencies) and the moving range chart are traditional in the sense that points beyond the upper control limit (UCL) and lower control limit (LCL) represent occurrences that are expected to happen less than three times in a thousand. The monthly murder frequencies for October 2009, March 2010 and May 2010 (appear as red circled points in Figure 12) exceed the UCL of the Individuals chart suggesting that, given the rest of the data included in the chart, these frequencies are odd or extreme. Or in control chart terms, signals are being sent at these times that indicate that the process may have changed and should be investigated. Similarly for the moving range portion of Figure 12, June and July of 2010 are signals suggesting that something may have changed. The moving range chart is in fact signaling 
that there was a significant drop in the frequency of murders from May 2010 to June 2010. The signal at July 2010 is a direct result of using a span of three intervals to calculate the moving range, but is also signaling that a change occurred from May 2010 to June 2010. The blue vertical line included in both the individual and moving range charts represents May 24, 2010 marking the joint JDF and JCF incursion into Tivoli Gardens. The time plot, augmented by control chart information, signals an increasing trend in murders leading up to 'The Incursion' and a subsequent significant drop in monthly murders following 'The Incursion'.

Table 5. Monthly Total Murder Victim frequencies for the period 2009-12

\begin{tabular}{|c|c|c|c|c|c|c|c|}
\hline \multirow{2}{*}{$\begin{array}{c}2009 \\
\text { Month }\end{array}$} & \multicolumn{3}{|c|}{2010} & \multirow{2}{*}{$\begin{array}{c}2011 \\
\text { Month }\end{array}$} & \multicolumn{3}{|c|}{2012} \\
\hline & Number & Month & Number & & Number & Month & Number \\
\hline Jan-09 & 121 & Jan-10 & 141 & Jan-11 & 92 & Jan-12 & 108 \\
\hline Feb-09 & 118 & Feb-10 & 110 & Feb-11 & 77 & Feb-12 & 95 \\
\hline Mar-09 & 120 & Mar-10 & 177 & Mar-11 & 73 & Mar-12 & 69 \\
\hline Apr-09 & 123 & Apr-10 & 137 & Apr-11 & 93 & & \\
\hline May-09 & 155 & May-10 & 184 & May-11 & 102 & & \\
\hline Jun-09 & 123 & Jun-10 & 98 & Jun-11 & 89 & & \\
\hline Jul-09 & 163 & Jul-10 & 86 & Jul-11 & 103 & & \\
\hline Aug-09 & 143 & Aug-10 & 82 & Aug-11 & 102 & & \\
\hline Sep-09 & 134 & Sep-10 & 78 & Sep-11 & 92 & & \\
\hline Oct-09 & 178 & Oct-10 & 108 & Oct-11 & 98 & & \\
\hline Nov-09 & 149 & Nov-10 & 127 & Nov-11 & 101 & & \\
\hline Dec-09 & 156 & Dec-10 & 114 & Dec-11 & 104 & & \\
\hline
\end{tabular}
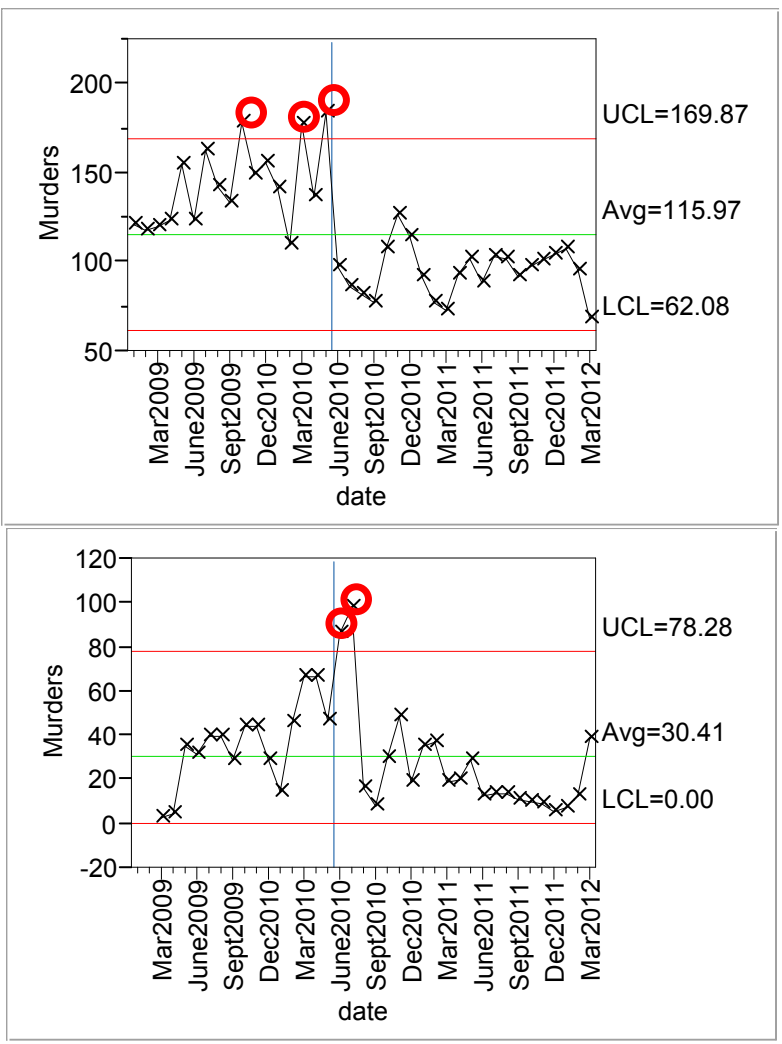

Individuals \& Moving Range Charts

Monthly Frequency of Murders January 1, 2009 - March 31, 2012

Figure 12. Individual and Moving Range Chart of Monthly Murders January 2009-March 2012
Similar to manufacturing practices, once an assignable cause has been identified through a control chart, the practice is then to remove the data associated with the assignable cause (in this case data prior to May 24, 2010) and reconstruct the control chart based on the remaining data. Figure 13 captures this action, as it continues to monitor the frequency of murders on a monthly basis now starting at June 2010. Note that there are no points beyond the control limits for either the individuals chart or the moving range chart (see Figure 13). As new data points become available (i.e., May 2012, June 2012, ...) these charts will be augmented with the data and the control limits recalculated. New data points will provide additional insights into monthly trends and the stability of the current murder rate. The initial control chart provided us with a signal that in fact something had changed in terms of the number of homicides committed on a monthly basis. Once identified it is quite straight forward to then look at the actual impact on the homicide rate in Jamaica.

To further investigate the signaled change in monthly murder rate, an Analysis of Variance (ANOVA) was conducted using the groupings 'Before' (i.e., the period January 1, 2009-May 31, 2010) and 'Post' (i.e., June 1, 2010-Mar 31, 2012). Figure 14 illustrates the monthly murder frequencies sorted into these two groupings. The plot is simply the monthly frequencies on the vertical axis and 'Before' and 'Post' May 24, 2010 on the horizontal axis. The green diamonds are statistical graphics that have several features. The horizontal width of the green 
diamonds is proportional to the number data points (in this case, months) included in the grouping. In this case there were seventeen months in the 'Before' grouping and twenty-two months in the 'Post' grouping. The horizontal line connecting the two vertices of the diamond at its widest point is the average of the monthly frequencies included in the grouping. For the 'Before' group, the average monthly number of murders is 143 and for the 'Post' group the average monthly number of murders is 95 . Since neither green diamond includes or overlaps with the overall average number of monthly murders (black horizontal line across the entire chart at 116), the chart suggests that the average number of monthly murders for the 'Before' group is significantly different than the average number of monthly murders for the 'Post' group. These graphic based interpretations are all verified in the ANOVA table ( $p$-value <0.0001) also included in Figure 14 Effectively these analyses indicate that since 'The Incursion', Jamaica averages 48 fewer murders per month.
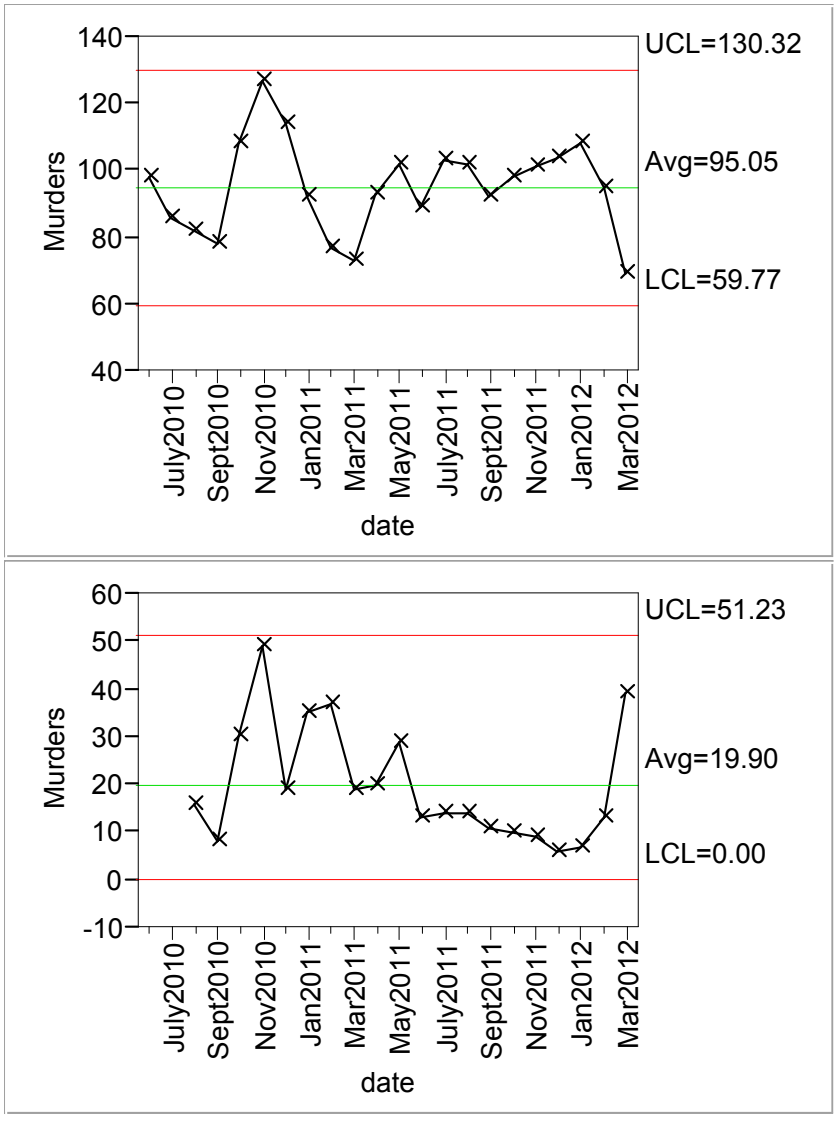

Individuals and Moving Range Charts

Monthly Frequency of Murders June 1, 2010 - March 31, 2012

Figure 13. Individual and Moving Range Chart of Monthly Murders June 2010-March 2012

In terms of homicide rates, prior to the incursion Jamaica saw 63.5 murders per 100,000 inhabitants, while following 'The Incursion' the rate dropped to 42 murders per 100,000 inhabitants.

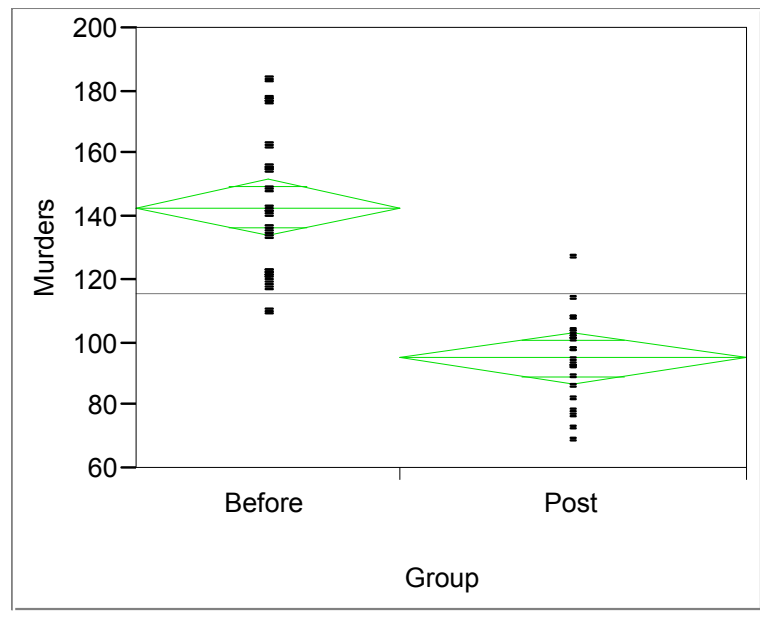

Analysis of Variance

\begin{tabular}{cccccc}
\hline Source & DF & Sum of Squares & Mean Square & F Ratio & Prob $>$ F \\
\hline Group & 1 & 22107.079 & 22107.1 & 65.1249 & $<.0001$ \\
Error & 37 & 12559.896 & 339.5 & & \\
C. Total & 38 & 34666.974 & & & \\
\hline
\end{tabular}

Means for Oneway Anova

\begin{tabular}{cccccc}
\hline Level & Number & Mean & Std Error & Lower 95\% & Upper 95\% \\
\hline Before & 17 & 143.059 & 4.4686 & 134.00 & 152.11 \\
Post & 22 & 95.045 & 3.9281 & 87.09 & 103.00 \\
\hline
\end{tabular}

Summary of Fit

\begin{tabular}{lc}
\hline Rsquare & $\mathbf{0 . 6 3 7 6 9 9}$ \\
\hline Root Mean Square Error & 18.42435 \\
Mean of Response & 115.9744 \\
Observations (or Sum Wgts) & 39 \\
\hline
\end{tabular}

Figure 14. 'Before' and 'Post' May 24, 2010, grouping of Monthly Murder Frequencies

\section{Conclusions}

Since 2009 homicide rates have been on the decline in Jamaica. In this manuscript we have attempted to identify, quantify and provide statistical evidence of the declines. Further the analyses provide direction in terms of age and geographic location that might assist in providing focus for the prevention of future homicides. For example targeted initiatives that focus on males in the age range of 20-29 in the parishes of Kingston \& St. Andrew, St. Catherine and St. James may have better success in reducing the homicide rate that an Island wide initiative.

Several views of currently available murder victim and perpetrator data have been presented with commentary designed to provide background and support for the statistical tools used. We welcome feedback on the analysis and the readers' inferences and/or conclusions drawn. All 
data has been included in order to encourage others to investigate and present additional views.

\section{References}

[1] United Nations Office on Drugs and Crime, 'Global Study on Homicide'. October, 2011.

[2] Vision 2030 Jamaica, National Development Plan, ISBN 978-976-8103-28-4, Planning Institute of Jamaica, Kingston 5, Jamaica, 2009.

[3] Jamaica Constabulary Force Statistics and Information Management Unit, 'Age Group and Gender for Victims of Major Crimes 2007-2011'. June, 2012.
[4] Jamaica Constabulary Force Statistics and Information Management Unit, 'Jamaica Constabulary Force Periodic Major Crime Statistics Review-January 1, 2012-March 31, 2012 and Comparison 2011, 2010 and 2009'. April, 2012.

[5] JAMStats2010, Electronic Database. Cited source: Jamaica Constabulary Force Statistics and Information Management Unit, 2011.

[6] Economic and Social Survey Jamaica, ISSN 0256-5013, Planning Institute of Jamaica, Kingston 5, Jamaica, 2012.

[7] The Jamaica Gleaner, 'Attack on State'. May 24, 2010.

[8] The Jamaica Gleaner, 'Tivoli incursion had an impact'. September 5, 2010. 